\title{
Effect of Proprioceptive Neuromuscular Facilitation Neck Pattern Exercises on Balance in Stroke - An Evidence Based Study
}

\author{
Twinkle Mahesh Mesaniya ${ }^{1}$ Jayshree Sutaria $^{2}$ \\ ${ }^{1}$ M.P.T. (Neurosciences), ${ }^{2}$ M.P.T. (Musculoskeletal), Lecturer, Government Spine Institute and Government \\ Physiotherapy College, Civil Hospital, Asarwa, Ahmedabad.
}

Corresponding Author: Twinkle Mahesh Mesaniya

\begin{abstract}
Background: Stroke is the sudden loss of neurological function which is caused by an interruption of blood flow to the brain. A variety of focal deficits are possible that include changes in level of consciousness and impairments of sensory, motor, cognitive, perceptual and language functions. Trunk muscles are impaired in the patients with stroke so there is diminished ability to maintain balance because of weakened muscle strength of trunk. Resistance to neck motion during PNF provides irradiation to the trunk muscles.

Purpose: The purpose is to study the scientific evidences regarding the effect of proprioceptive neuromuscular facilitation neck pattern exercises on balance in stroke.

Methodology: A search for relevant articles was carried out using key words- Neck proprioceptive neuromuscular facilitation, Balance, Trunk control and Stroke. Search engines used were Google Scholar, PubMed, PEDro, ScienceDirect and ResearchGate. Studies were selected from year 2011-2020. Eight studies were included in which there were 6 randomized control trial, 1 case series, 1 single subject design.

Results: All the 8 articles concluded that proprioceptive neuromuscular facilitation neck pattern exercise is effective in improving balance in the patients with stroke. (level of evidence $: 1 \mathrm{~b}, 2 \mathrm{a}, 4,5)$

Conclusion: Based on evidences, it can be concluded that proprioceptive neuromuscular facilitation neck pattern exercise is found to be effective in improving balance in the patients with stroke.
\end{abstract}

Clinical Implication: Proprioceptive neuromuscular facilitation neck pattern exercises can be used as an adjunct to other treatment in improving balance in stroke.

Key Words: Neck proprioceptive neuromuscular facilitation, Balance, Trunk control and Stroke.

\section{INTRODUCTION}

Stroke is classically characterized as a neurological deficit which is attributed to an acute focal injury of the central nervous system (CNS) by a vascular cause that includes cerebral infarction, intracerebral haemorrhage $(\mathrm{ICH})$ and subarachnoid haemorrhage (SAH). It is a major cause of disability and death worldwide. ${ }^{[1]}$ To be classified as stroke, the neurological deficits should persist for at least 24 hours. ${ }^{[2]}$

There are variety of focal deficits are, including changes in the level of consciousness and impairments of sensory, motor, cognitive, perceptual and language functions, postural control and balance problems and bowel and bladder dysfunction. ${ }^{[2]}$

Stroke is one of the major causes of death and disability in India. The estimated prevalence rate of stroke is, $84-262 / 100,000$ in rural and 334-424/100,000 in urban areas (2013). The incidence rate is 119$145 / 100,000 .^{[3]}$ Stroke represented $1.2 \%$ of total deaths in India. ${ }^{[4]}$

Balance is the condition in which all the forces acting on the body are balanced in 
such a way that the centre of mass $(\mathrm{COM})$ is within the boundaries of the base of support (BOS). Stroke patients suffer from balance disability due to the result of the abnormalities in the proprioceptive system, sensory system, trunk muscles and muscles of the limbs. Reduction in the activity of the muscles of the trunk reduces movement of the pelvis which leads to the development of asymmetry of the trunk and preventing use of strategies that protects against the risk of balance loss. ${ }^{[5]}$

Trunk is the central key point of the body and its strength is impaired multi directionally in hemiplegic patients. This impaired strength affects the balance in these patients. ${ }^{[6]}$

Proprioceptive Neuromuscular

Facilitation (PNF) is an approach to therapeutic exercise that combines functionally placed diagonal patterns of movement with techniques of neuromuscular facilitation to produce the motor responses and improve neuromuscular control and function. Resistance to the stronger muscle groups of diagonal pattern facilitates the responsiveness of the weaker muscle groups ${ }^{[7]}$ Properly applied resistance results in irradiation. Irradiation is the spread of the response to stimulation. Resistance to neck motion provides irradiation to the trunk muscle. $^{[8]}$

\section{METHODOLOGY}

Study Type: This is an Evidence Based Study, conducted according to Preferred Reporting Items for Systematic Reviews and Meta-analysis (PRISMA) guidelines (Figure 1).

Search strategy: The search engines used to find the appropriate articles were: Google Scholar, PubMed, PEDro, ScienceDirect and ResearchGate.
Key words used for the search were Neck proprioceptive neuromuscular facilitation, Balance, Trunk control and Stroke.

Eligibility criteria: Articles were selected from last 10 years (2011-2020). Total 127 articles were found, out of which 12 articles were relevant. Out of 12 articles, 8 articles were included in the study (Table 1). Other articles were excluded because they used limb proprioceptive neuromuscular facilitation and they did not include any outcome for balance.

Data Analysis: All the 8 articles were assessed using 2 scales:

(1). The PEDro scale: It assesses methodological quality and consists of a checklist of 11 criteria, 10 of which are scored. For each criterion the study met, 1 point was awarded. The points were tallied and presented as a score out of 10. The scale applies only to experimental studies. For this review, investigations with PEDro scores of 6 to 10 were considered high quality, of 4 to 5 were considered moderate quality, and of 0 to 3 were considered low quality. The PEDro score has demonstrated 'fair' to 'excellent' inter-rater reliability (Intraclass Correlation Coefficient 0.530.91) for randomized controlled trials of physiotherapy interventions. Convergent validity is supported for the PEDro score through correlation with other quality rating scales including: the Jadad scale (0.35) and van Tulder 2003 scale (0.71) for clinical trials of physiotherapy related interventions. ${ }^{[9]}$ (Appendix 1)

(2). The CEBM's Levels of Evidence scale: It assesses quality based on study design, which categorize the studies in a scale ranging from 1 to 5 with further subdivision for each. (Appendix 2) 
Twinkle Mahesh Mesaniya et.al. Effect of proprioceptive neuromuscular facilitation neck pattern exercises on balance in stroke - an evidence based study.

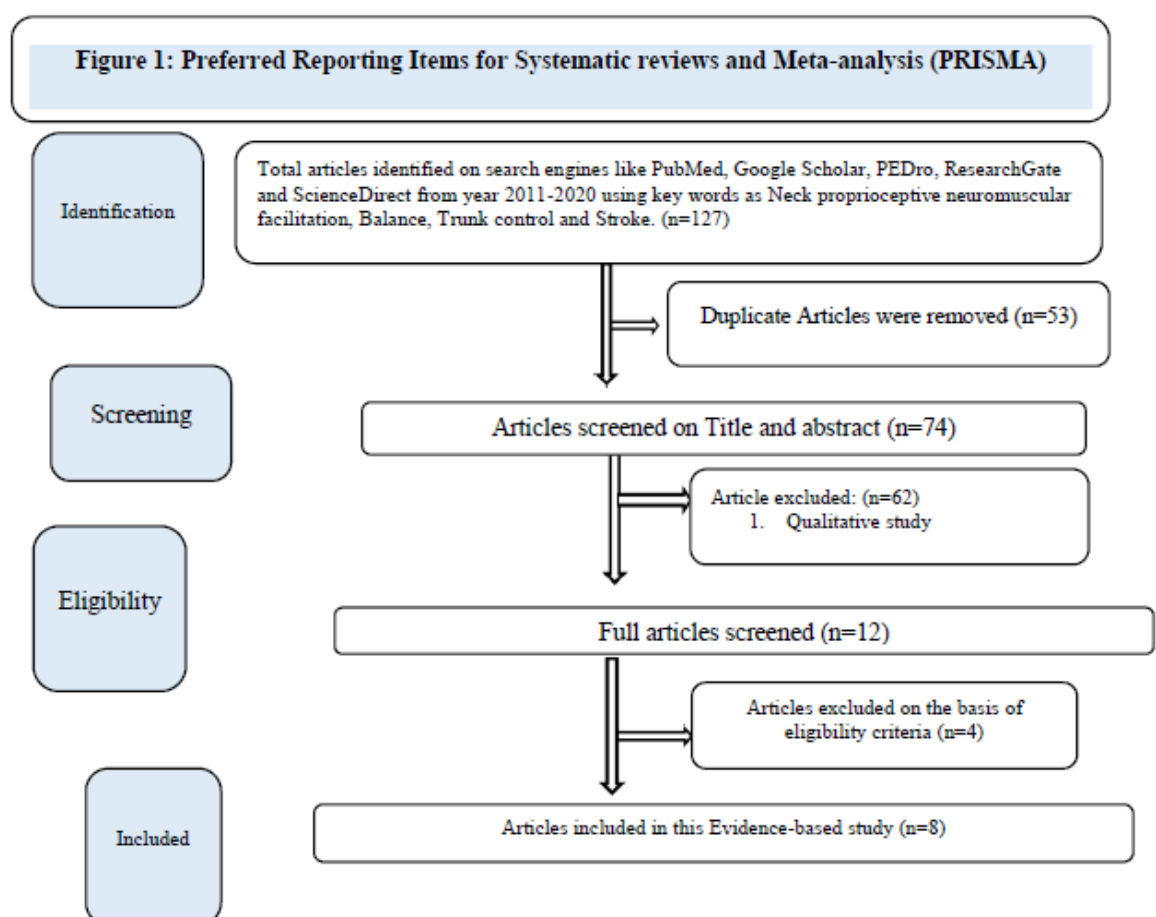

Characteristics of included studies

\begin{tabular}{|c|c|c|c|c|c|c|}
\hline $\begin{array}{l}\text { Sr. } \\
\text { no }\end{array}$ & Title & $\begin{array}{l}\text { Study } \\
\text { design }\end{array}$ & $\begin{array}{l}\text { Sample } \\
\text { size }\end{array}$ & $\begin{array}{l}\text { Treatment } \\
\text { duration }\end{array}$ & $\begin{array}{l}\text { Main outcome } \\
\text { measures }\end{array}$ & $\begin{array}{l}\text { Level of } \\
\text { evidence\& } \\
\text { PEDro }\end{array}$ \\
\hline 1 & $\begin{array}{l}\text { Effects of Eye Movement with PNF Neck } \\
\text { Movement on Trunk Stability and Standing } \\
\text { Position Balance Ability of Chronic Stroke } \\
\text { Patients. }{ }^{[10]}\end{array}$ & RCT & $\mathrm{n}=30$ & $\begin{array}{l}60 \text { min, } \\
3 \text { times a week } \\
\text { for } 8 \text { weeks }\end{array}$ & $\begin{array}{l}\text { TIS } \\
\text { BBS } \\
\text { FRT } \\
\text { COP } \\
\text { LOS }\end{array}$ & $\begin{array}{l}1 \mathrm{~b} \\
\text { Score }=6\end{array}$ \\
\hline 2 & $\begin{array}{l}\text { The Effect of Neck Pattern of PNF on } \\
\text { Balance and Walking Ability in Patients } \\
\text { with Chronic Stroke. }\end{array}$ & RCT & $\mathrm{n}=14$ & $\begin{array}{l}20 \text { minutes /day, } \\
\text { five days/week, } \\
\text { for } 4 \text { weeks }\end{array}$ & $\begin{array}{l}\text { BBS and gait } \\
\text { parameters }\end{array}$ & $\begin{array}{l}2 \mathrm{a} \\
\text { Score }=5\end{array}$ \\
\hline 3 & $\begin{array}{l}\text { Effect of a Neck Proprioceptive } \\
\text { Neuromuscular } \\
\text { Program on the Body Postitaral Stability in } \\
\text { Elite Female Basketball Players. }{ }^{[12]}\end{array}$ & RCT & $\mathrm{n}=30$ & $\begin{array}{l}12 \text { sessions per } \\
\text { week for } 4 \text { weeks }\end{array}$ & Biodex balance test & $\begin{array}{l}2 \mathrm{a} \\
\text { Score }=5\end{array}$ \\
\hline 4 & $\begin{array}{l}\text { The Effects of a Neck Exercise using a PNF } \\
\text { Neck Pattern on the Balance and Numbness } \\
\text { of Both the Upper Extremities and Neck } \\
\text { Motions in Patients with Cervical } \\
\text { Myelopathy. }\end{array}$ & $\begin{array}{l}\text { Single } \\
\text { Subject } \\
\text { Design. }\end{array}$ & $\mathrm{n}=1$ & $\begin{array}{l}60 \text { minutes per } \\
\text { day, } 3 \text { times per } \\
\text { week for } 8 \text { weeks }\end{array}$ & $\begin{array}{l}\text { one-leg stand test } \\
\text { and VAS }\end{array}$ & 5 \\
\hline 5 & $\begin{array}{l}\text { Effects of proprioceptive neuromuscular } \\
\text { facilitation neck pattern exercise on the } \\
\text { ability to control the trunk and maintain } \\
\text { balance in chronic stroke patients. }{ }^{[14]}\end{array}$ & RCT & $\mathrm{n}=30$ & $\begin{array}{l}\text { Three times a } \\
\text { week for six } \\
\text { weeks }\end{array}$ & TIS and BBS & $\begin{array}{l}1 \mathrm{~b} \\
\text { Score }=6\end{array}$ \\
\hline 6 & $\begin{array}{l}\text { Effect of eye movements and proprioceptive } \\
\text { neuromuscular facilitation on balance and } \\
\text { head alignment in stroke patients with } \\
\text { neglect syndrome. }{ }^{[15]}\end{array}$ & RCT & $\mathrm{n}=20$ & $\begin{array}{l}\text { five times each } \\
\text { week for } 6 \text { weeks }\end{array}$ & $\begin{array}{l}\text { BioRescue } \\
\text { apparatus } \\
\text { (SyCoMORe, } \\
\text { France) } \\
\text { CVA and CRA }\end{array}$ & $\begin{array}{l}2 \mathrm{a} \\
\text { Score }=5\end{array}$ \\
\hline 7 & $\begin{array}{l}\text { Effects of oculo-motor exercise, functional } \\
\text { electrical stimulation and proprioceptive } \\
\text { neuromuscular stimulation on visual } \\
\text { perception of spatial neglect patients. }{ }^{[16]}\end{array}$ & RCT & $\mathrm{n}=30$ & $\begin{array}{l}5 \text { times per week } \\
\text { for } 6 \text { weeks }\end{array}$ & $\begin{array}{l}\text { LBT, MVPT, and } \\
\text { CBS }\end{array}$ & $\begin{array}{l}2 \mathrm{a} \\
\text { Score }=5\end{array}$ \\
\hline 8 & $\begin{array}{l}\text { Neck proprioceptive training for balance } \\
\text { function in patients with chronic poststroke } \\
\text { hemiparesis: a case series. }{ }^{[17]}\end{array}$ & $\begin{array}{l}\text { A case } \\
\text { series }\end{array}$ & $\mathrm{n}=3$ & $\begin{array}{l}30 \text { min daily, five } \\
\text { times per week } \\
\text { for } 4 \text { weeks }\end{array}$ & $\begin{array}{l}\text { Tetrax system and } \\
\text { TUG and } \\
\text { proprioception tests. }\end{array}$ & 4 \\
\hline
\end{tabular}

\section{RESULTS}

Evidences were reviewed and analysis was done based on PEDro score and CEBM's Level of Evidence Scale.
Articles were selected from last 10 years (2011-2020). Total 127 articles were found, out of which 12 articles were 
relevant. Out of 12 articles, 8 articles were included in the study

All the 8 studies concluded that neck PNF is more effective than a control group receiving conventional treatment.

\section{DISCUSSION}

Total 8 studies were reviewed from various data sources and included in this evidence-based study. The methodological qualities of included studies were low to high. (level of evidence :1b,2a,4,5) Sample size varied from 1 to 30 . Treatment sessions varied from 18 to 30 sessions.

There are 6 moderate to high quality of evidences (Randomized control trial $-1 b$, 2a) which suggest that proprioceptive neuromuscular facilitation neck pattern exercise is an effective treatment in improving the ability to control the trunk, coordination of arms and legs, walking ability and balance in stroke patients.

One single subject design and one case series (level of evidence -4 and 5) shows that proprioceptive neuromuscular facilitation neck pattern exercise is an effective treatment in improving balance and neck motion.

All the 8 articles concluded that proprioceptive neuromuscular facilitation neck pattern exercise is effective in improving balance in the patients with stroke. (level of evidence : $1 b, 2 a, 4,5$ )

The main principle evident can be defined from the work irradiation. Irradiation is the spread of the response from stronger muscle group to the weaker muscle. Resistance to neck motion provides irradiation to the trunk muscles and thus improves the ability to control the trunk. Improvement in the ability to control the trunk is necessary to enhance the ability to balance as trunk is the central key point of the body. ${ }^{[14]}$

Also, the neck muscles play an important role in maintaining posture and walking. The receptors in the neck muscles are involved in maintaining posture. The muscles in the neck have an especially high proprioception sense compared to other muscles in the body, such as the small muscles in the hands or eyes. Changes in the neck position of the stroke patient are associated with changes in posture control, and it is believed that, the trunk stability and thus balance is increased due to the increase of the proprioceptive sense input by the movement, in various directions, with the proprioceptive movement of the neck. ${ }^{[11]}$

It should be noted that no studies reported adverse effect of PNF neck pattern exercises.

\section{CONCLUSION}

Based on evidences on following search engines like PEDro, Google scholar, PubMed, Research gate, Science direct and the Cochrane library from the year 2011 2020, it can be concluded that proprioceptive neuromuscular facilitation neck pattern exercises is found to be effective in improving balance in the patients with stroke.

\section{Clinical Implication:}

Proprioceptive neuromuscular facilitation neck pattern exercises can be used as an adjunct to other treatment in improving balance in stroke.

\section{Conflict of Interest}

There is no conflict of interest.

\section{Ethical Approval}

Ethical approval was not required.
ABBREVIATIONS
PNF: Proprioceptive neuromuscular facilitation; PEDro: Physiotherapy Evidence Database; CEBM: Center of Evidence Based Medicine; RCT: Randomized Controlled Trial; PRISMA: Preferred Reporting Items for systematic reviews and meta-analysis; TIS: Trunk Impairment Scale; BBS: Berg Balance Scale; FRT: Functional Reach Test; COP: Centre Of Pressure; LOS: line of support; VAS: Visual Analogue Scale; CVA:; CRA:; LBT:; MVPT:; CBS:; TUG: Timed Up and Go test. 
Acknowledgement: None

\section{Source of Funding: None}

\section{REFERENCES}

1. Sacco RL, Kasner SE, Broderick JP, Caplan LR, Connors JJ, Culebras A, Elkind MS, George MG, Hamdan AD, Higashida RT, Hoh BL. An updated definition of stroke for the 21st century: a statement for healthcare professionals from the American Heart Association/American Stroke Association. Stroke. 2013 Jul;44(7):2064-89.

2. Susan B. O Sullivan, Physical rehabilitation, 5th edition, Jaypee brothers' medical publications, 2007, chapter 18, pg. 705-776.

3. Jeyaraj Durai Pandian and Paulin Sudhanb, Stroke Epidemiology and Stroke Care Services in India, Journal Of Stroke 2013, Vol 15(3)pg-128-134

4. Tapas k Banerjee and Shyamal K Das, "Epidemiology of stroke in India", Neurology Asia, 2006, vol (11)pg 1-4

5. Bae SH, Lee HG, Kim YE, Kim GY, Jung HW, Kim KY. Effects of trunk stabilization exercises on different support surfaces on the cross-sectional area of the trunk muscles and balance ability. Journal of physical therapy science. 2013 Jun 25;25(6):741-5.

6. Karthikbabu S, Chakrapani M, Ganeshan S, Rakshith KC, Nafeez S, Prem V. A review on assessment and treatment of the trunk in stroke: A need or luxury. Neural regeneration research. 2012 Sep 5;7(25):1974.

7. Carolyn Kisner and Lynn Allen Colby. Therapeutic exercises: Foundations and techniques, fifth edition; Davis Company, 2007 Chapter 6 and 8, pg. 251-269, 195-202

8. Susan S. Adler, Dominiek Beckers, Math Buck: PNF in Practice; An Illustrated Guide. Third edition. Springer, 2008, chapter 1,2 and 9, pg. 1-18,155-168

9. Aidan Cashin, James H Mcauley. Clinimetrics: Physiotherapy Evidence Database (PEDro) scale, Journal of physiotherapy, September 2019.

10. Kim DH, Kim KH, Lee SM. Effects of Eye Movement with PNF Neck Movement on Trunk Stability and Standing Position Balance Ability of Chronic Stroke Patients. Physikalische
Rehabilitationsmedizin, Kurortmedizin. 2019 Oct 28;23.

11. Bang DH, Song MS. The Effect of Neck Pattern of PNF on Balance and Walking Ability in Patients with Chronic Stroke. PNF and Movement. 2019;17(1):47-56.

12. Naderifar H, Minoonejad H, Barati AH, Lashay A. Effect of a neck proprioceptive neuromuscular facilitation training program on body postural stability in elite female basketball players. Journal of Rehabilitation Sciences \& Research. 2018 Jun 1;5(2):41-5.

13. Park SE, Lim WT, Moon SH. The Effects of a Neck Exercise using a PNF Neck Pattern on the Balance and Numbness of Both the Upper Extremities and Neck Motions in Patients with Cervical Myelopathy-Single Subject Design. PNF and Movement. 2018;16(3):333-43.

14. Hwangbo PN, Kim KD. Effects of proprioceptive neuromuscular facilitation neck pattern exercise on the ability to control the trunk and maintain balance in chronic stroke patients. Journal of physical therapy science. 2016;28(3):850-3.

15. Park SE, Min KO, Lee SB, Choi WS, Kim SH. Effect of eye movements and proprioceptive neuromuscular facilitation on balance and head alignment in stroke patients with neglect syndrome. Journal of Physical Therapy Science. 2016;28(2):596601.

16. Park SE, Oh DS, Moon SH. Effects of oculo-motor exercise, functional electrical stimulation and proprioceptive neuromuscular stimulation on visual perception of spatial neglect patients. Journal of physical therapy science. 2016;28(4):1111-5.

17. Kim GM, Oh DW. Neck proprioceptive training for balance function in patients with chronic poststroke hemiparesis: a case series. Journal of physical therapy science. 2014;26(10):1657-9.

How to cite this article: Mesaniya TM, Sutaria J. Effect of proprioceptive neuromuscular facilitation neck pattern exercises on balance in stroke - an evidence based study. International Journal of Science \& Healthcare Research. 2021; 6(3): 48-53. DOI: https://doi.org/10. 52403/ijshr.20210709 
Twinkle Mahesh Mesaniya et.al. Effect of proprioceptive neuromuscular facilitation neck pattern exercises on balance in stroke - an evidence based study.

\section{APPENDIX 1-PEDro SCALE}

\begin{tabular}{|l|l|l|}
\hline No. & Description & Yes / No \\
\hline 1 & Eligibility criteria were specified (No points awarded) & \\
\hline 2 & Subjects were randomly allocated to groups & \\
\hline 3 & Allocation was concealed & \\
\hline 4 & The groups were similar at baseline regarding the most important prognostic indicators & \\
\hline 5 & There was blinding of all subjects & \\
\hline 6 & There was blinding of all therapists who administered the therapy & \\
\hline 7 & There was blinding of all assessors who measured at least one key outcome & \\
\hline 8 & Measure of at least one key outcome were obtained from more than 85\% of the subjects initially allocated to groups & \\
\hline 9 & All subjects for whom outcome measures were available received the treatment or control condition as allocated & \\
\hline 10 & The result of between group comparisons are reported for at least one key outcome & \\
\hline 11 & The study provides both point measures and measures of variability for at least one key outcome & \\
\hline
\end{tabular}

\section{APPENDIX 2- CEBM'S LEVEL OF EVIDENCE}

\begin{tabular}{|l|l|}
\hline Level & Definition \\
\hline 1a & Systematic reviews of randomized controlled trials \\
\hline 1b & Individual randomized controlled trials \\
\hline 1c & All-or-none studies \\
\hline 2a & Systematic reviews of cohort studies \\
\hline $2 \mathrm{~b}$ & Individual cohort studies or low-quality randomized controlled trials \\
\hline $2 \mathrm{c}$ & Outcome research \\
\hline $3 \mathrm{a}$ & Systematic reviews of case-control studies \\
\hline $3 \mathrm{~b}$ & Individual case-control studies \\
\hline 4 & Case series, poorly designed cohort or case-control studies \\
\hline 5 & Animal and bench research, expert opinion \\
\hline
\end{tabular}

$* * * * * *$ 